\title{
Theoretical X-Ray Photoelectron and Emission Spectra of C-, N-, and O-Containing Polymers by Density-Functional Theory Calculations using Model Molecules
}

\author{
Shingo ShIMAdA, Tomonori IDA, Kazunaka Endo, Masahiko SuHARA, \\ Ernst Z. KURMAEV, ${ }^{*}$ and Delano P. CHONG** \\ Department of Chemistry, Faculty of Science, Kanazawa University, Kanazawa 920-1192 Japan, \\ *Institute of Metal Physics, Russian Academy of Sciences-Ural Division 620219 Yekaterinburg \\ GSP-170 Russia, and **Department of Chemistry, 2036 Main Mall, University of British \\ Columbia, Vancouver, BC, Canada V6T 121
}

(Received July 10, 2000; Accepted August 31, 2000)

\begin{abstract}
The X-Ray photoelectron and emission spectra (XPS, XES) of C-, N-, and O-containing polymers [polyvinyl alcohol (PVA), polyethylene oxide (PEO), and dianhydride-4,4'-oxydianiline (PMDA-ODA)] were simulated by deMon density-functional theory (DFT) calculations using the model molecules. The theoretical valence photoelectron and $\mathrm{C}, \mathrm{N}$, and $\mathrm{O} \mathrm{K} \alpha \mathrm{X}$-Ray emission spectra showed good agreement with some experimental ones. The combined analysis of the valence XPS and $\mathrm{C}, \mathrm{N}$, and $\mathrm{O} \mathrm{K} \alpha$ XES enables us to divide the observed valence electronic distribution into the individual contributions for $\mathrm{p} \sigma-, \mathrm{p} \pi$ - and non-bonding MOs of the polymers.
\end{abstract}

KEY WORDS XES and XPS / Polymer (PVA, PEO, PMDA-ODA) / Electronic State /

Organic polymers are now used as active materials with useful applications in widely demanding fields of electronics, catalysis, biotechnology, and space. As a first step of an investigation, it is important to obtain information on the electronic states of the polymers. X-Ray photoelectron and emission spectroscopies are powerful tools for providing precise information on the electronic states of polymers. These experimental electron spectra of polymers are directly linked to the theoretical results of the electronic states as obtained by MO calculations using model oligomers, since polymers consist of the repetition units.

In recent studies using deMon density-functional theory (DFT) program ${ }^{1}$ which uses the idea of transitionstate ${ }^{2}$ Chong and co-workers ${ }^{3-7}$ offered the method of calculating accurate vertical ionization potentials (VIPs) and core-electron binding energies (CEBEs) of isolated molecules in gas. Until now we analyzed the X-Ray photoelectron spectra (XPS) of seventy polymers by the DFT calculations using model oligomers in our previous representative works. ${ }^{8-15}$ The studies ${ }^{9-15}$ showed better assignments of XPS of polymers using deMon DFT calculations, because we used the energy shift $W D$ (work function $(W)$ and other energies (delta, $D))^{8-15}$ to account for solid-state effects. The simulation of the valence spectra was performed on the model molecules using standard convolution by each Gaussian line shape and using the Gelius intensity model ${ }^{16}$ for molecular photo-ionization cross sections. The line width of each peak of ionization energy $I_{\mathrm{k}}$ was taken to be $0.10 I_{\mathrm{k}}$ (proportional to the ionization energy) as stated in previous works. ${ }^{8,9}$

Some studies ${ }^{18-23}$ have been made using both X-Ray photoelectron and emission spectroscopies in oligomers and polymers. Ultra-soft X-Ray emission spectroscopy demonstrated that the technique provides a means of extracting chemical information in the form of molecular orbital population owing to the dipole selection rules and the localization of core-hole states. Studies of X-Ray emission spectra (XES) of polymers can be realized using only fluorescence measurements because of damage of polymer target under electron excitation. However, the relatively low fluorescence yield and instrument efficiencies associated with registration of XES of light elements require an intense excitation photon source that has limited the activity in this field. The recent development of third generation synchrotron sources has provided us with the kind of incident photon intensity necessary to overcome the low signal strength inherent to these kinds of measurements. ${ }^{23}$

In the present work, we perform the simulation for XES and valence XPS of three polymers [polyvinyl alcohol (PVA), polyethylene oxide (PEO) and dianhydride-4, 4'-oxydianiline (PMDA-ODA)] by deMon density functional calculations using the model molecules. One of aims of this study is to compare the experimental XES and valence XPS with the theoretical simulation results using the model molecules. In PVA and PEO polymers, they differ by the position of the oxygen atom relative to the carbons in the monomeric unit. The structural differences will be reflected in distributions of the XPS and XES. For PMDA-ODA, the polymer is one of the most popular and fundamental chemical structure of the polyimides. The analysis gives useful knowledge to the understanding of valence XPS and XES of polyimides in general. We will show that the combined analysis of the valence XPS and $\mathrm{C}, \mathrm{N}$, and $\mathrm{O} \mathrm{K} \alpha \mathrm{XES}$ enables us to divide the observed valence electronic distribution into the individual contributions for $\mathrm{p} \sigma-, \mathrm{p} \pi$ - and non-bonding MOs of the polymers.

\section{THEORETICAL BACKGROUND}

For the comparison between calculations for a single molecule of the model and experiments on a solid, we must shift each computed vertical ionization potentials (VIPs), $\Gamma_{\mathrm{k}}$ by a quantity $W D$ as $I_{\mathrm{k}}(\mathrm{EF})=\Gamma_{\mathrm{k}}-W D$, to convert to ionization energy $I_{\mathrm{k}}(\mathrm{EF})$ relative to the Fermi level. This quantity WD denotes the sum of the work 
function of the sample and other energy effects, as stated in our previous studies. $^{8-15}$

\section{Core-Electron Binding and Emission Energies and VIPs for XPS and XES}

In order to obtain the accurate CEBEs, we used the generalized transition-state (GTS) method. In the GTS method, Williams and co-workers ${ }^{24}$ proposed the extension of Slater's transition-state method ${ }^{2}$ and approximated the endothermicity $\Delta E=E(1)-E(0)$ by

$$
\Delta E=[F(0)+3 F(2 / 3)] / 4,
$$

where $F(x)=\partial E(x) / \partial x$, and $x(0<x \leq 1)$ is assumed to be a continuous variable, with $E(0)$ and $E(1)$ denoting the energies of the initial and final states, respectively. For example, for the ionization of an electron from molecular orbital (MO) $\phi_{\mathrm{k}}$ of interest, $x$ represents the fraction of electron removed, and, according to the Janak theorem, ${ }^{25} F(x)$ is the negative orbital energy $\varepsilon_{\mathrm{k}}(x)$. This procedure is applied in the following way. In the unrestricted generalized transition-state (uGTS) method, we removed $2 / 3 \alpha$ electron from MO $\phi_{\mathrm{k}}$ of interest.

Following Chong, ${ }^{4-7}$ we used the uGTS model to compute CEBEs and added relativistic correction $\left(C_{\text {rel }}\right)$ for $\mathrm{C}$ to $\mathrm{F}$ using $C_{\mathrm{rel}}=K I_{\mathrm{nr}}{ }^{N}$ where $K=2.198 \times 10^{-7}, N=2.178$, and $I_{\mathrm{nr}}$ is the non-relativistic CEBE.

For the VIPs of the valence regions, we use the socalled restricted diffuse ionization ( $\mathrm{rDI}$ ) model which Asbrink et al. ${ }^{26}$ proposed in the HAM/3 method. In the rDI model, as indicated in our previous studies, ${ }^{8-15}$ half of an electron is removed evenly from the valence MOs and the negative of the resulting orbital energies correspond to calculated VIPs. This allows us to obtain all the valence VIPs in a single calculation.

In the case of $\mathrm{C}$ and $\mathrm{O} \mathrm{K} \alpha \mathrm{X}$-Ray emission energy, we obtain the calculated values from the differences $\left[(\mathrm{CEBE})_{1 \mathrm{~s}}-\left(\mathrm{VIP}, I_{\mathrm{k}}\right)_{\mathrm{j}[2 \mathrm{p}(\mathrm{A})]}\right]$ between CEBEs of the hole and VIPs of electrons to fill up the hole.

\section{Intensity of XPS and XES}

The intensity of valence XPS was estimated from the relative photo-ionization cross section for $\mathrm{Al} \mathrm{K} \alpha$ radiation using the Gelius intensity model. ${ }^{16}$ For the relative atomic photo-ionization cross-section, we used the theoretical values from Yeh. ${ }^{27}$

Although the polymer sample studied here contains $\mathrm{H}$, $\mathrm{C}, \mathrm{N}$, and $\mathrm{O}$ atoms, we consider only core holes of $\mathrm{C}, \mathrm{N}$, and $\mathrm{O}$ atoms. Thus, in the case of $\mathrm{O}, \mathrm{N}$, and $\mathrm{C} \mathrm{K} \alpha$ spectra, the XES transition arises from outer occupied $p$ orbitals to s-type holes in a given atom, due to the selection rule $\Delta l= \pm 1$. The intensity can be written as:

$$
\begin{aligned}
& I_{\mathrm{ij}} \propto\left|\int \phi_{\mathrm{i}}{ }^{\mathrm{c}}(r)(e r) \phi_{\mathrm{j}}(r) \mathrm{d} \tau\right|^{2} \\
& \quad=N\left|\int \Sigma_{\mathrm{A}} X_{1 \mathrm{~s}(\mathrm{~A})}(r)(e r) \Sigma_{\mathrm{p}(\mathrm{A})} C_{\mathrm{jp}(\mathrm{A})} X_{(\mathrm{A})}(r) \mathrm{d} \tau\right|^{2},
\end{aligned}
$$

where $\phi_{\mathrm{i}}{ }^{\mathrm{c}}(r)$ and $\phi_{\mathrm{j}}(r)$ is a core hole and an outer valence MOs, respectively. $N$ denotes a normalization factor, and $C_{\mathrm{jp}(\mathrm{A})}$ is the LCAO coefficient of the atomic orbital $X_{\mathrm{p}(\mathrm{A})}(r)$ centered on atom A. In order to calculate each intensity of XES for model molecules at each emission energy, we used the STO-3G basis set for each atom of the model molecules.
Considering the selection rule and neglecting the terms involving orbital products on different atoms, an approximate intensity $I_{1 \mathrm{~s}(\mathrm{~A}) \mathrm{j}}$ is given by;

$$
I_{1 \mathrm{~s}(\mathrm{~A}) \mathrm{j}}=N^{\prime} \Sigma_{\mathrm{A}}\left|C_{\mathrm{j}[2 \mathrm{p}(\mathrm{A})] 1}\right|^{2},
$$

where $N^{\prime}$ is a normalization factor, which includes the units of atomic dipole intensities. Thus, the XES intensity of carbon, nitrogen, and oxygen spectral lines was obtained by summing the LCAO populations $P_{\mathrm{j}[2 \mathrm{p}(\mathrm{A})] 1}$ of the atomic orbitals $\chi_{2 \mathrm{p}(\mathrm{A})}(r)$ centered on given carbon, nitrogen and oxygen atoms; $l=x, y$, and $z$.

\section{CALCULATION DETAILS}

Recently we know that for organic molecules the geometrical optimization by AM1 method ${ }^{28}$ corresponds well to the experimental values. In the case of solving the non-linear equations involving a Hartree-Fock-like DFT one, we think it is a best way to select a better initial condition. As indicated in previous works, ${ }^{8-15}$ we have performed the better assignments of XPS for seventy polymers by DFT calculations using the model molecules after the geometrical optimization with a semiempirical AM1 method. ${ }^{28}$

Model molecules $\left[\mathrm{H}-\left(\mathrm{CH}_{2}-\mathrm{CHOH}\right)_{3}-\mathrm{H}, \mathrm{H}-\left(\mathrm{CH}_{2} \mathrm{CH}_{2}-\right.\right.$ $\mathrm{O})_{3}-\mathrm{H}, \quad \mathrm{C}_{22} \mathrm{O}_{5} \mathrm{~N}_{2} \mathrm{H}_{12}$ (monomer)] of PVA, PEO, and PMDA-ODA polymers were calculated using deMon DFT program. ${ }^{1}$ For the geometry of the molecules, we used the optimized cartesian coordinate from the semiempirical AM1 (version 6.0) method. ${ }^{28}$ For PVA, we used the syndiotactic model molecule, since we concluded in our previous works $8,10,11$ that, within the X-Ray photoelectron instrumental resolution of $0.5 \mathrm{eV}$, we are able to simulate the XPS of polymers by the MO and DFT calculations using one of three stereoisomers as the model molecules, due to the insensitivity of the spectra to tacticity.

DeMon calculations were performed with the exchange-correlation potential labeled as B 88/P 86, made from Becke's 1988 exchange functional ${ }^{29}$ and Perdew's 1986 correlation functional. ${ }^{30}$ In the program, we used a nonrandom grid and polarized valence double- $\zeta$ (DZVP) basis of $\left(621 / 41 / 1^{*}\right)$ for $\mathrm{C}, \mathrm{N}$, and $\mathrm{O}$, and (41) for $\mathrm{H}$ with auxiliary fitting functions labeled $(4,4 ; 4,4)$ for $\mathrm{C}$ and $\mathrm{O}$, and $(3,1 ; 3,1)$ for $\mathrm{H}$. In order to calculate each intensity of XES for model molecules at each emission energy, we used the STO-3G basis set for each atom of the model molecules.

To simulate the valence XPS and XES of the polymers theoretically, we constructed from a superposition of peaks centered on each VIP, $I_{\mathrm{k}}$ and each emission energy, $\left[(\mathrm{CEBE})_{1 \mathrm{~s}}-\left(\mathrm{VIP}, I_{\mathrm{k}}\right)_{\mathrm{j}[2 \mathrm{p}(\mathrm{A})]}\right]$. As was done in previous work, ${ }^{8-15}$ each peak was represented by a Gaussian curve. In the case of the linewidth (WH( $(k))$, we used WH $(k)=0.10 I_{\mathrm{k}}$ (proportinal to the ionization energy) and $\mathrm{WH}(k)=1.3 \mathrm{eV}$ (experimental resolution) for valence XPS and XES, respectively.

For experimental spectra, we cited the valence XPS and all XES in the works due to the references. ${ }^{17,19,20,31}$ The XES of the polyimide were made use of the high brightness available at Lawrence Berkeley National Laboratory's Advanced Light Source (ALS). 
Table I. Calculated peaks, VIP, main AO photoionization cross-section, orbital nature and the functional group for valence XPS of PVA

\begin{tabular}{|c|c|c|c|c|}
\hline Observed peak & Calculated peak & Main AO photoioni- & Orbital nature & Functionaloroun \\
\hline $\mathrm{eV}$ & $\mathrm{VIP} / \mathrm{eV}$ & zation cross section & Urbital nature & Functional group \\
\hline $\begin{array}{l}26.0 \\
(23-29)\end{array}$ & $29.03-27.61$ & $\mathrm{O}_{2 \mathrm{~s}}(0.8), \mathrm{C}_{2 \mathrm{~s}}(0.1)$ & $\mathrm{s} \sigma\left(\mathrm{O}_{2 \mathrm{~s}}-\mathrm{C}_{2 \mathrm{~s}}\right)-\mathrm{B}$ & $-\mathrm{O}^{-} \mathrm{C}$ \\
\hline $\begin{array}{l}19.0 \\
(15-20)\end{array}$ & $22.68-20.17$ & $\mathrm{C}_{2 \mathrm{~s}}(0.7), \mathrm{O}_{2 \mathrm{~s}}(0.1)$ & $\mathrm{s} \sigma\left(\mathrm{C}_{2 \mathrm{~s}}-\mathrm{C}_{2 \mathrm{~s}}\right)-\mathrm{B}$ & $\begin{array}{l}-\mathrm{C}(\text { main chain }) \\
-\mathrm{C}-\mathrm{O}\end{array}$ \\
\hline $\begin{array}{l}14.0 \\
(12-15)\end{array}$ & $18.53-15.86$ & $\begin{array}{l}\mathrm{C}_{2 \mathrm{~s}}(0.5), \mathrm{O}_{2 \mathrm{p}}(0.4) \\
\mathrm{C}_{2 \mathrm{~s}}(0.1)\end{array}$ & $\begin{array}{l}\mathrm{p} \sigma\left(\mathrm{C}_{2 \mathrm{~s}}-\mathrm{O}_{2 \mathrm{p}}\right)-\mathrm{B} \\
\mathrm{p} \sigma\left(\mathrm{C}_{2 \mathrm{~s}}-\mathrm{C}_{2 \mathrm{p}}\right)-\mathrm{B}\end{array}$ & $\begin{array}{l}-\mathrm{C}-\mathrm{O},-\mathrm{C} \text { (main chain) } \\
-\mathrm{C} \text { (main chain) }\end{array}$ \\
\hline \multirow{3}{*}{$\begin{array}{l}(5-12) \\
\text { shoulder }\end{array}$} & below 16.21 & $\mathrm{O}_{2 \mathrm{p}}, \mathrm{C}_{2 \mathrm{~s}}, \mathrm{C}_{2 \mathrm{p}}$ & $\begin{array}{l}\mathrm{p} \sigma\left(\mathrm{C}_{2 \mathrm{~s}}-\mathrm{O}_{2 \mathrm{p}}\right)-\mathrm{B} \\
\mathrm{p} \pi\left(\mathrm{C}_{2 \mathrm{p}}-\mathrm{O}_{2 \mathrm{p}}\right)-\mathrm{B}\end{array}$ & $\begin{array}{l}-\mathrm{C}-\mathrm{O} \\
-\mathrm{C}-\mathrm{O}\end{array}$ \\
\hline & $9.84-9.42$ & $\mathrm{O}_{2 p}$ & $\mathrm{p} \pi$ (lone-pair)-NB & $-\mathrm{C}-\mathrm{O}$ \\
\hline & $8.87-8.20$ & $\mathrm{O}_{2 p}$ & $\mathrm{p} \pi$ (lone-pair)-NB & $-\mathrm{O}-\mathrm{C}$ \\
\hline
\end{tabular}

WD (difference between observed and calculated peaks) was assumed as $3.0 \mathrm{eV}$.

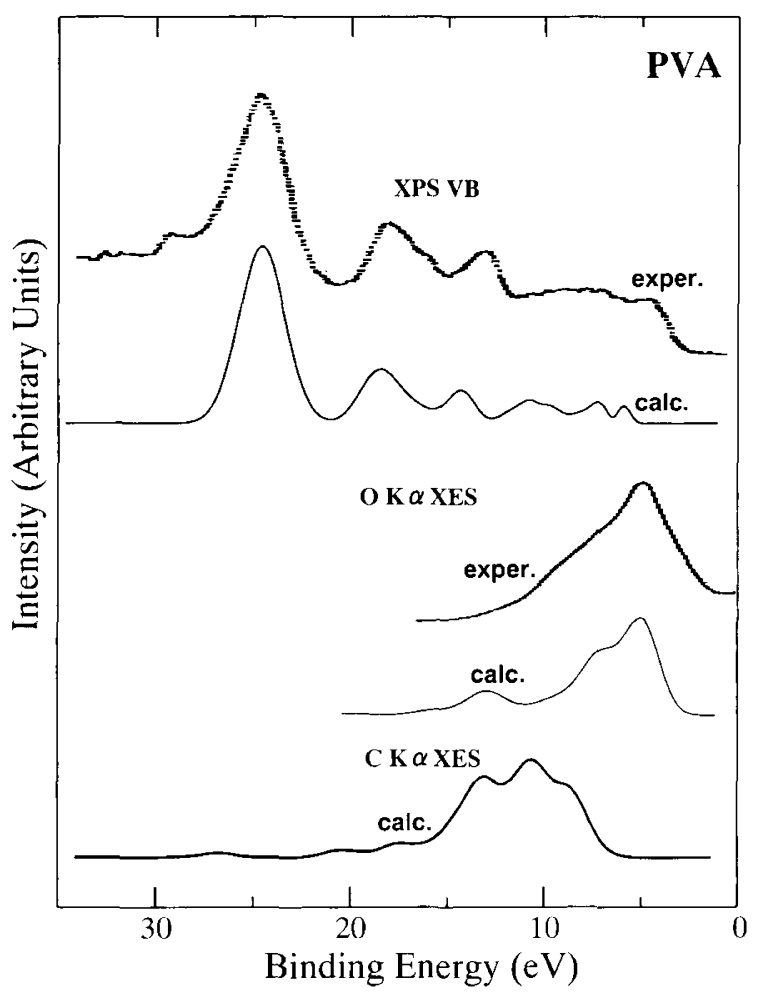

Figure 1. Calculated and experimental valence X-Ray photoelectron and emission $\mathrm{O} \mathrm{K} \alpha$ and $\mathrm{C} \mathrm{K} \alpha$ spectra of polyvinyl alcohol.

\section{RESULTS AND DISCUSSION}

In the previous works, ${ }^{4}$ we analyzed the valence XRay photoelectron spectra (XPS) of polymers by deMon DFT program using the model molecules. In the works, we were not sufficiently able to distinguish the $2 p$ electron distribution in the range of $2-12 \mathrm{eV}$ among various orbital contributions, since the spectra of the pcontribution are very low intensities due to the small relative values of the atomic photo-ionization crosssection to that of the 2 s-electrons. We have divided the observed valence electronic distribution into the individual contributions for $\mathrm{p} \sigma-, \mathrm{p} \pi$ - and non-bonding MOs of the polymers from the combined analysis of the valence XPS and $\mathrm{C}, \mathrm{N}$, and $\mathrm{O} \mathrm{K} \alpha$ XES for the $\mathrm{C}-, \mathrm{N}-$, and $\mathrm{O}-$ containing polymers by deMon DFT calculations using the model molecules, respectively.

\section{Polyvinyl Alcohol}

It is known that spectra exhibiting triad tacticity are obtained for PVA using ${ }^{1} \mathrm{H}$ and ${ }^{13} \mathrm{C}$ NMR measurements. Previous studies ${ }^{32-34}$ described peaks within methine groups of signals that are due to stereochemical sequence effects: Endo and co-workers ${ }^{34}$ determined the probabilities for the existence of three stereoisomers (syndiotactic, heterotactic, and isotactic types) as 0.51 , 1.00 , and 0.31 , respectively, from the integrated intensities of the three methine of ${ }^{1} \mathrm{H}$ and ${ }^{13} \mathrm{C}$ splitting signals for a commercially-available PVA sample. However, in our previous works, ${ }^{8,10,11}$ we concluded that, within the $\mathrm{X}$-Ray photoelectron instrumental resolution of $0.5 \mathrm{eV}$, we are able to simulate the XPS of polymers by the MO and DFT calculations using one of three stereoisomers as the model molecules, due to the insensitivity of the spectra to tacticity. This means that the valence XPS of polymers is too insensitive to distinguish the stereoisomers.

In Figure 1, we showed theoretical and experimental XPS and XES of PVA in the range of $0-35 \mathrm{eV}$. Since experimental peaks of valence XPS in the figure are divided into four regions, we summarized the parameters (calculated VIPs, main AO photo-ionization crosssection, orbital nature and functional groups) of their corresponding peaks in Table I. For the experimental shoulder peak of XPS at around $28 \mathrm{eV}$, we neglected it, because the peak results from the Na2p AOs of impurities in PVA. In the case of the valence XPS, the most intensive peak at around $26.0 \mathrm{eV}$ corresponds to the photoionization cross-section of $\mathrm{O} 2 \mathrm{~s}$ AOs from $\mathrm{s} \sigma(\mathrm{O} 2 \mathrm{~s}-\mathrm{C} 2 \mathrm{~s})$ and $\mathrm{p} \sigma(\mathrm{O} 2 \mathrm{~s}-\mathrm{C} 2 \mathrm{p})$ bonding orbitals which are due to $\left(-\mathrm{O}^{-}\right.$ C) functional groups. The middle intensive peaks at around 19.0 and $14.0 \mathrm{eV}$ result from the $\mathrm{s} \sigma(\mathrm{C} 2 \mathrm{~s}-\mathrm{C} 2 \mathrm{~s})$ and $\mathrm{p} \sigma(\mathrm{C} 2 \mathrm{~s}-\mathrm{O} 2 \mathrm{p}, \mathrm{C} 2 \mathrm{p})$ bonding orbitals, respectively. For the shoulder peak in the range of $5-13.5 \mathrm{eV}$, we were not sufficiently able to distinguish the experimental 2p-electron distributions, since the spectra of pcontributions are very low intensities due to the small relative values of the atomic photo-ionization crosssection to that of 2 s-electrons. However, we can determine $2 p$-contributions in detail from theoretical and experimental analysis of the $\mathrm{O} 1 \mathrm{~s} \mathrm{~K} \alpha \mathrm{X}$-Ray emission spectrum which corresponds to the shoulder peak of valence 


\section{PVA}

(a)

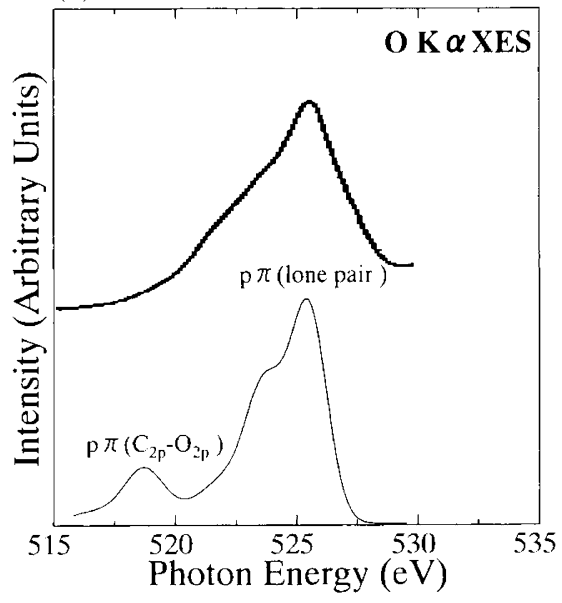

(b)

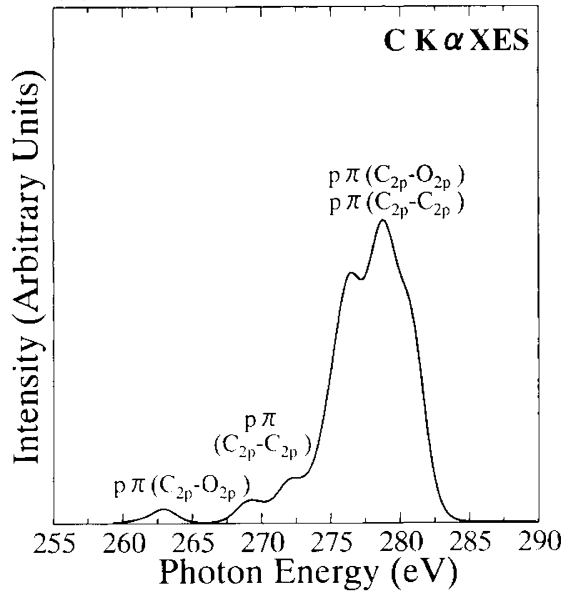

Figure 2. Calculated and experimental X-Ray emission spectra of polyvinyl alcohl (a) O K $\alpha$ XES (b) C K $\alpha$ XES.

Table II. Observed peaks, emission energy, orbital nature, and functional group for X-Ray emission spectra of PVA

a) O K $\alpha$ XES

\begin{tabular}{lcll}
\hline $\begin{array}{c}\text { Observed peak } \\
\mathrm{eV}\end{array}$ & $\begin{array}{c}\text { Emission energy } \\
{[(\mathrm{CEBE})-(\mathrm{VIP})] / \mathrm{eV}}\end{array}$ & Orbital nature & Functional group \\
\hline 526.0 & 528.9 & $\mathrm{p} \pi$ (lone-pair)-NB & $-\mathrm{O}-\mathrm{C}$ \\
$(525-530)$ & 527.1 & $\mathrm{p} \pi\left(\mathrm{C}_{2 \mathrm{p}}-\mathrm{O}_{2 \mathrm{p}}\right)-\mathrm{B}$ & $\mathrm{C}-\mathrm{O}^{-}$ \\
\hline $\begin{array}{l}\text { (517-525) } \\
\text { shoulder }\end{array}$ & 525.1 & $\mathrm{p} \pi\left(\mathrm{C}_{2 \mathrm{p}}-\mathrm{O}_{2 \mathrm{p}}\right)-\mathrm{B}$ & $-\mathrm{C}-\mathrm{O}$ \\
\hline
\end{tabular}

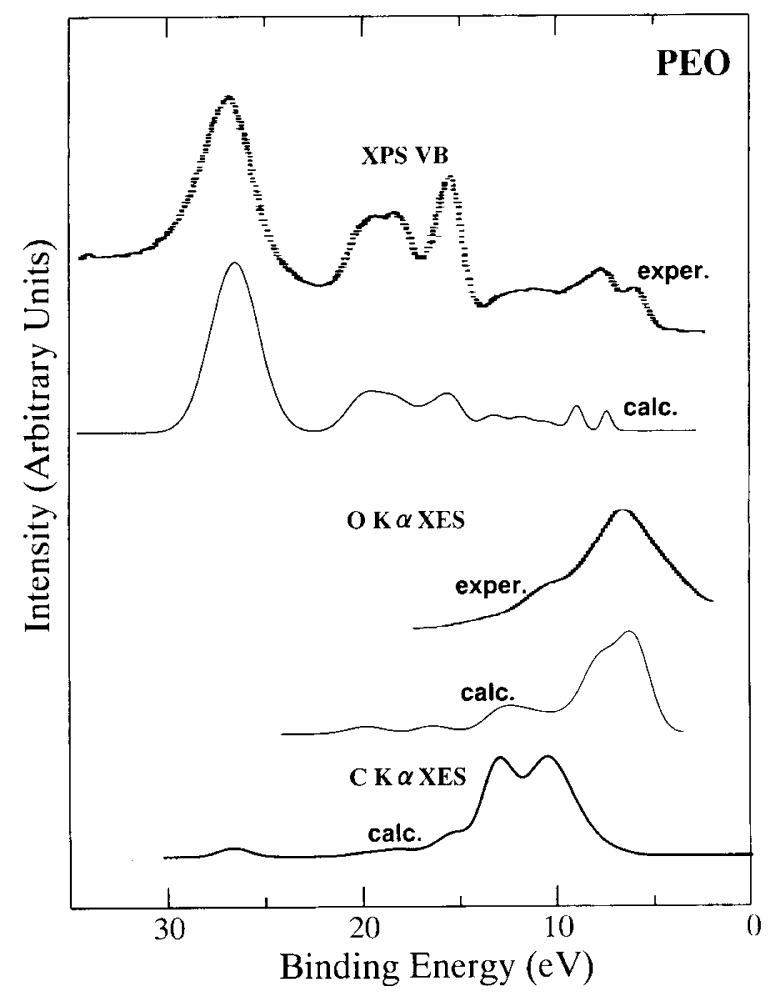

Figure 3. Calculated and experimental valence X-Ray photoelectron and emission $\mathrm{O} \mathrm{K} \alpha$ and $\mathrm{C} \mathrm{K} \alpha$ spectra of polyethylene oxide.

\begin{tabular}{ccc} 
b) $\mathrm{C} \mathrm{K} \alpha$ XES & \\
\hline $\begin{array}{c}\text { Emission energy } \\
{[(\mathrm{CEBE})-(\mathrm{VIP})] / \mathrm{eV}}\end{array}$ & Orbital nature & Functional group \\
\hline 280.8 & $\mathrm{p} \pi\left(\mathrm{C}_{2 \mathrm{p}}-\mathrm{O}_{2 \mathrm{p}}\right)-\mathrm{B}$ & $\mathrm{C}-\mathrm{O}-$ \\
$\mathrm{p} \pi\left(\mathrm{C}_{2 \mathrm{p}}-\mathrm{C}_{2 \mathrm{p}}\right)-\mathrm{B}$ & $-\mathrm{C}-\mathrm{C}^{-}$ \\
\hline 276.2 & $\mathrm{p} \pi\left(\mathrm{C}_{2 \mathrm{p}}-\mathrm{O}_{2 \mathrm{p}}\right)-\mathrm{B}$ & $\mathrm{C}-\mathrm{O}^{-}$ \\
\hline 271.9 & $\mathrm{p} \pi\left(\mathrm{C}_{2 \mathrm{p}}-\mathrm{C}_{2 \mathrm{p}}\right)-\mathrm{B}$ & $-\mathrm{C}-\mathrm{C}^{-}$ \\
\hline 263.5 & $\mathrm{p} \pi\left(\mathrm{C}_{2 \mathrm{p}}-\mathrm{O}_{2 \mathrm{p}}\right)-\mathrm{B}$ & $\mathrm{C}-\mathrm{O}^{-}$ \\
\hline
\end{tabular}

XPS in Figure 1.

For $\mathrm{O} 1 \mathrm{~s} \mathrm{~K} \alpha \mathrm{XES}$, simulated spectra are in a considerably good accordance with the experimental ones in Figure 2a. Especially, for the simulated peak due to $\mathrm{p} \pi$ bonding orbitals at around $518 \mathrm{eV}$, the difference between the calculated and experimental emission energy may amount to $4.5 \mathrm{eV}$, since the differences between the calculated and experimental values are in errors of \pm 2.2 $\mathrm{eV}$ using double- $\zeta$ (DZVP) basis. In the $\mathrm{O} 1 \mathrm{~s} \mathrm{~K} \alpha$, we classified the orbital nature of emission spectrum into two ranges of $525-530$, and $515-525 \mathrm{eV}$. The two regions are due to $\mathrm{p} \pi$-non-bonding and $\mathrm{p} \pi$-bonding orbitals which result from lone pair of oxygen and $\mathrm{O}-\mathrm{C}$ functional groups. In Table II a, we showed observed peaks, emission energy, orbital nature, and functional group for O1s $\mathrm{K} \alpha$ XES of PVA. In Figure $2 b$ and Table II $b$, we also gave simulated spectrum of $\mathrm{C} 1 \mathrm{~s} \mathrm{~K} \alpha \mathrm{X}$-Ray emission, and calculated emission energy, orbital nature, and functional groups, respectively, although the experimental emission spectra are not yet obtained.

\section{Polyethylene Oxide}

We will analyze the shape of the valence XPS and XES spectra of PEO, compare it with the results on PVA just discussed, and attempt to relate the differences to structural isomerism on the basis of the theoretical results on the model molecules. The theoretical and experimental valence electron and X-Ray emission spectra of PEO were shown in Figures 3 and 4. In Figures. 1 and 3, the 
PEO

(a)

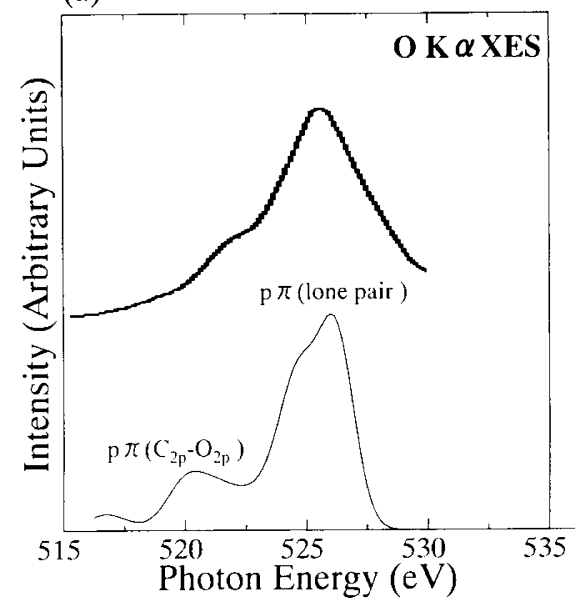

(b)

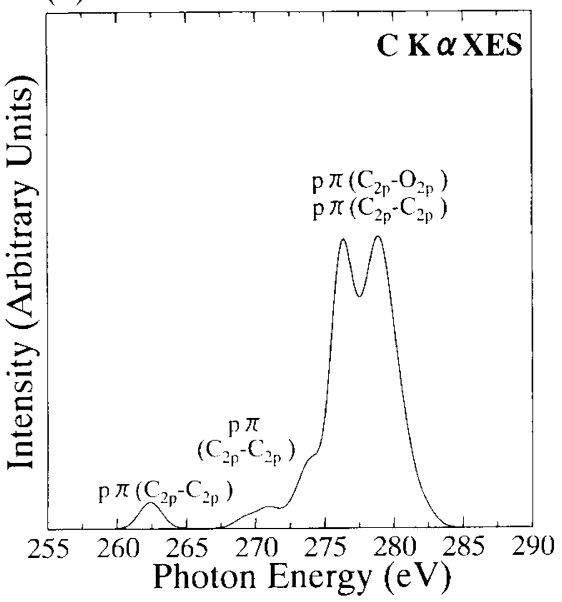

Figure 4. Calculated and experimental X-Ray emission spectra of polyethylene oxide (a) O K $\alpha$ XES (b) C K $\alpha$ XES.

Table III. Calculated peaks, VIP, main AO photoionization cross-section, orbital nature and the functional group for valence XPS of PEO

\begin{tabular}{|c|c|c|c|c|}
\hline Observed peak & Calculated peak & Main AO photoioni- & Orbital nature & Functional group \\
\hline $\mathrm{eV}$ & $\mathrm{VIP} / \mathrm{eV}$ & & & \\
\hline $\begin{array}{l}26.0 \\
(24-30)\end{array}$ & $28.99-28.02$ & $\mathrm{O}_{2 \mathrm{~s}}(0.7), \mathrm{C}_{2 \mathrm{~s}}(0.2)$ & $\mathrm{s} \sigma\left(\mathrm{O}_{2 \mathrm{~s}}-\mathrm{C}_{2 \mathrm{~s}}\right)-\mathrm{B}$ & $-\mathrm{O}-\mathrm{C}$ \\
\hline $\begin{array}{l}18.0 \\
(16-20)\end{array}$ & $21.95-20.08$ & $\mathrm{C}_{2 \mathrm{~s}}(0.7), \mathrm{O}_{2 \mathrm{~s}}(0.1)$ & $\mathrm{s} \sigma\left(\mathrm{C}_{2 \mathrm{~s}}-\mathrm{O}_{2 \mathrm{~s}}, \mathrm{C}_{2 \mathrm{~s}}\right)-\mathrm{B}$ & $\begin{array}{l}-\mathrm{C}(\text { main chain }) \\
-\mathrm{C}-\mathrm{O}\end{array}$ \\
\hline $\begin{array}{l}14.0 \\
(12-15.5)\end{array}$ & $18.41-15.41$ & $\mathrm{C}_{2 \mathrm{~s}}(0.6), \mathrm{O}_{2 \mathrm{p}}$ & $\begin{array}{l}\mathrm{p} \sigma\left(\mathrm{C}_{2 \mathrm{~s}}-\mathrm{O}_{2 \mathrm{p}}\right)-\mathrm{B} \\
\mathrm{p} \sigma\left(\mathrm{C}_{2 \mathrm{~s}}-\mathrm{C}_{2 \mathrm{p}}\right)-\mathrm{B}\end{array}$ & $\begin{array}{l}-\mathrm{O}-\mathrm{C} \\
-\mathrm{C}(\text { main chain })\end{array}$ \\
\hline & $14.97-12.53$ & $\mathrm{C}_{2 \mathrm{p}}(0.8), \mathrm{O}_{2 \mathrm{p}}(0.2)$ & $\mathrm{p} \pi\left(\mathrm{C}_{2 \mathrm{p}}-\mathrm{O}_{2 \mathrm{p}}\right)-\mathrm{B}$ & $-\mathrm{C}-\mathrm{O}$ \\
\hline$(7-12)$ & $12.42-10.23$ & $\mathrm{C}_{2 \mathrm{p}}(0.5), \mathrm{O}_{2 \mathrm{p}}(0.4)$ & $\mathrm{p} \pi\left(\mathrm{C}_{2 \mathrm{p}}-\mathrm{O}_{2 \mathrm{p}}\right)-\mathrm{B}$ & $-\mathrm{C}-\mathrm{O}$ \\
\hline $\begin{array}{l}6.0 \\
(5-7) \\
\end{array}$ & $10.02-8.83$ & $\mathrm{O}_{2 \mathrm{p}}(0.8)$ & $\mathrm{p} \pi$ (lone-pair)-NB & $-\mathrm{O}-\mathrm{C}$ \\
\hline $\begin{array}{l}4.0 \\
(3-5)\end{array}$ & $8.64-8.49$ & $\mathrm{O}_{2 \mathrm{p}}(0.8)$ & $\mathrm{p} \pi$ (lone-pair)-NB & $-\mathrm{O}-\mathrm{C}$ \\
\hline
\end{tabular}

WD (difference between observed and calculated peaks) was assumed as $3.0 \mathrm{eV}$.

characteristic differences of the spectra between PEO and PVA are seen in the two ranges of $10-20$ and $4-10$ $\mathrm{eV}$ for their valence XPS. In the former region $(10-20$ $\mathrm{eV}$ ) of valence XPS, the peak of PEO at around $14 \mathrm{eV}$ is more intensive than that of PVA. It can be seen in the latter range $(4-10 \mathrm{eV})$ of the figures that the spectrum of PEO has three peaks at around 4,6 , and $9 \mathrm{eV}$, while that of PVA is a flat shoulder. This is due to the structural difference of oxygen atoms relative to the carbons in the monomeric unit.

In the case of the O1s K $\alpha$ XES in Figures 2a and 4a, we can see the different energy positions for shoulder emission peaks of PVA and PEO, respectively in the range of $520-525 \mathrm{eV}$. The simulation results almost seem to reflect such experimental positions of the peaks. For the simulated peak due to $\mathrm{p} \pi$-bonding orbitals at around $520 \mathrm{eV}$, the difference between the calculated and experimental emission energy may amount to 2.0 $\mathrm{eV}$, because the differences are in errors of $\pm 2.2 \mathrm{eV}$ using double- $\zeta$ (DZVP) basis. In Tables III and IV, we showed the parameters [(calculated VIPs, main AO photoionization cross-section, orbital nature and functional group) and (calculated emission energy, orbital nature, and functional groups) to the observed peaks for valence XPS and XES, respectively.

\section{PMDA-ODA Polyimide}

We showed the theoretical valence XPS and $\mathrm{C}, \mathrm{N}$, and O K $\alpha$ XES of a polyimide (PMDA-ODA) by deMon DFT calculations with experimental ones in Figures 5 and 6. Tables V and VI summarized the parameters [(calculated VIPs, main AO photoionization cross-section, orbital nature and functional group) and (calculated emission energy, orbital nature, and functional groups) to the observed peaks for valence XPS and each XES, respectively. These comparisons show that there are good agreements between experimentally obtained and theoretically calculated valence photoelectron and X-Ray emission spectra.

As indicated in previous works ${ }^{19,20}$ by semiempirical MO calculations, our theoretical analysis of the electronic states for valence XPS of PMDA-ODA is also in reasonable agreement with an earlier work, ${ }^{35}$ while it differs from the results of the PMDA-ODA system by SCF MO calculations. ${ }^{36,37}$ According to the MO calculations, ${ }^{36,37}$ they analyzed that the peak at around $9.5 \mathrm{eV}$ 
Table IV. Observed peaks, emission energy, orbital nature, and functional group for X-Ray emission spectra of PEO

a) $\mathrm{O} \mathrm{K} \alpha \mathrm{XES}$

\begin{tabular}{|c|c|c|c|}
\hline Observed peak & Emission energy & \multirow{2}{*}{ Orbital nature } & \multirow{2}{*}{ Functional group } \\
\hline $\mathrm{eV}$ & {$[(\mathrm{CEBE})-(\mathrm{VIP})] / \mathrm{eV}$} & & \\
\hline \multirow{2}{*}{$\begin{array}{l}526.0 \\
(522.5-530)\end{array}$} & 529.0 & $\mathrm{p} \pi$ (lone-pair)-NB & $-\mathrm{O}-\mathrm{C}$ \\
\hline & 527.4 & $\mathrm{p} \pi\left(\mathrm{C}_{2 \mathrm{p}}-\mathrm{O}_{2 \mathrm{p}}\right)-\mathrm{B}$ & $-\mathrm{C}-\mathrm{O}$ \\
\hline \multirow{2}{*}{$\begin{array}{l}(515-522.5) \\
\text { shoulder }\end{array}$} & 524.2 & $\mathrm{p} \pi\left(\mathrm{C}_{2 \mathrm{p}}-\mathrm{O}_{2 \mathrm{p}}\right)-\mathrm{B}$ & $\mathrm{C}^{-} \mathrm{O}^{-}$ \\
\hline & 519.4 & $\mathrm{p} \pi\left(\mathrm{O}_{2 \mathrm{p}}-\mathrm{C}_{2 \mathrm{p}}\right)-\mathrm{B}$ & $\mathrm{O}^{-} \mathrm{C}^{-}$ \\
\hline
\end{tabular}

b) $\mathrm{C} \mathrm{K} \alpha \mathrm{XES}$

\begin{tabular}{ccc}
$\begin{array}{c}\text { Emission energy } \\
{[(\mathrm{CEBE})-(\mathrm{VIP})] / \mathrm{eV}}\end{array}$ & Orbital nature & Functional group \\
\hline 280.5 & $\mathrm{p} \pi\left(\mathrm{C}_{2 \mathrm{p}}-\mathrm{C}_{2 \mathrm{p}}\right)-\mathrm{B}$ & $-\mathrm{C}-\mathrm{C}-$ \\
$\mathrm{p} \pi\left(\mathrm{C}_{2 \mathrm{p}}-\mathrm{O}_{2 \mathrm{p}}\right)-\mathrm{B}$ & $\mathrm{C}-\mathrm{O}-$ \\
\hline 277.0 & $\mathrm{p} \pi\left(\mathrm{C}_{2 \mathrm{p}}-\mathrm{C}_{2 \mathrm{p}}\right)-\mathrm{B}$ & $-\mathrm{C}-\mathrm{C}^{-}$ \\
\hline 271.9 & $\mathrm{p} \pi\left(\mathrm{C}_{2 \mathrm{p}}-\mathrm{C}_{2 \mathrm{p}}\right)-\mathrm{B}$ & $-\mathrm{C}-\mathrm{C}-$ \\
\hline 263.3 & $\mathrm{p} \pi\left(\mathrm{C}_{2 \mathrm{p}}-\mathrm{C}_{2 \mathrm{p}}\right)-\mathrm{B}$ & $-\mathrm{C}-\mathrm{C}-$ \\
\hline
\end{tabular}

\section{PMDA-ODA}

(a)

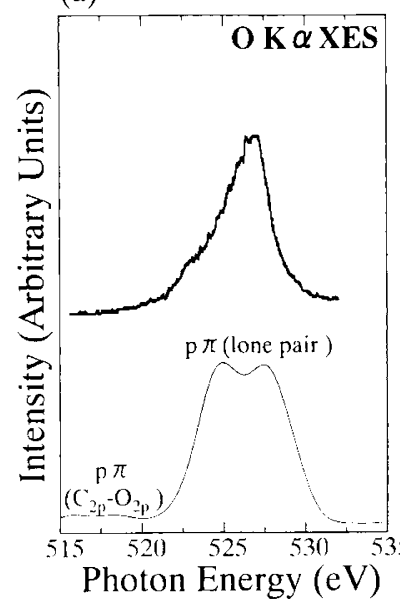

(b)

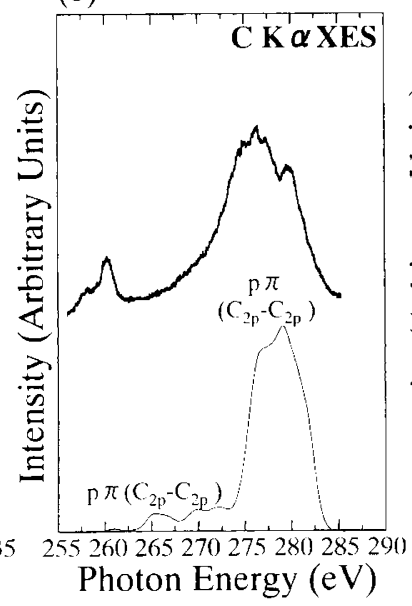

(c)

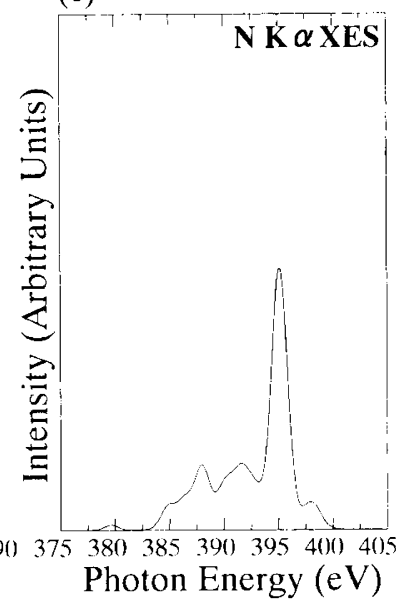

Figure 6. Calculated and experimental X-Ray emission spectra of PMDA-ODA polyimide (a) O K $\alpha$ XES (b) C K $\alpha$ XES (c) N K $\alpha$ XES.

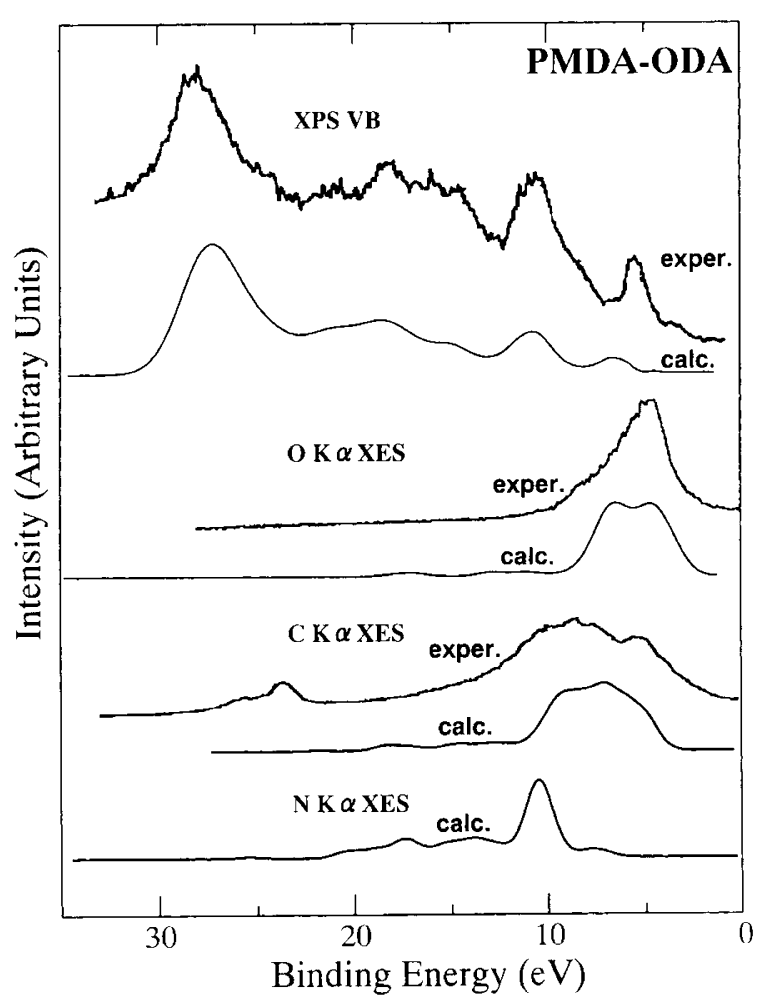

Figure 5. Calculated and experimental valence $X-$ Ray photoelectron and emission $\mathrm{O} \mathrm{K} \alpha, \mathrm{C} \mathrm{K} \alpha$, and $\mathrm{N} \mathrm{K} \alpha$ spectra of PMDA-ODA polyimide. is due to the $\mathrm{O} 2 \mathrm{p}$ non-bonding orbitals of lone pair electrons, while our DFT calculations show in Table $\mathrm{V}$ that the peaks at around 9.5 and 4.5 result from $\mathrm{p} \pi(\mathrm{C} 2 \mathrm{p}$ O2p)-bonding and $\mathrm{p} \pi$ (lone-pair)-non-bonding orbitals, respectively. This is an important result for understanding adhesion in these metal-polymer interfaces, especially for analyzing the formation of metal-polymer complexes by participating oxygen atoms.

The validity of the DFT calculations is determined by comparison with experimental valence XPS, C, and O $\mathrm{K} \alpha$ XES for PMDA-ODA. This comparison is shown in Figure 6, and offers good agreement for our interpretation of the valence photoelectron peaks based on our deMon DFT calculations. The energy position of the intensity maximum of the $\mathrm{O} \mathrm{K} \alpha$ XES exactly coincides with the peak of valence XPS at around $4.5 \mathrm{eV}$. The DFT calculations of $\mathrm{C}$ and $\mathrm{O} \mathrm{K} \alpha$ XES reproduce the fine structure and energy positions of the main peaks of the experimental spectra quite well. For the $\mathrm{O} \mathrm{K} \alpha \mathrm{XES}$, we were able to reproduce the wing, shoulder and intense peaks listed in Table VI.

\section{CONCLUSIONS}

We have determined the bond nature and the electron structures of PVA, PEO, and PMDA-ODA from combined analysis of valence XPS and $\mathrm{C}, \mathrm{N}$, and $\mathrm{O} \mathrm{K} \alpha \mathrm{XES}$. In particular, the combined analysis enables us to divide the valence electronic distribution into the individual 


\section{S. SHimada et al.}

Table V. Calculated peaks, VIP, main AO photoionization cross-section, orbital nature and the functional group for valence XPS of PMDAODA

\begin{tabular}{|c|c|c|c|c|}
\hline$\frac{\text { Observed peak }}{\mathrm{eV}}$ & $\frac{\text { Calculated peak }}{\text { VIP/eV }}$ & $\begin{array}{l}\text { Main AO photoioni- } \\
\text { zation cross section }\end{array}$ & Orbital nature & Functional group \\
\hline $\begin{array}{l}27.0 \\
(24-32)\end{array}$ & $27.33-24.13$ & $\begin{array}{l}\mathrm{O}_{2 \mathrm{~s}}(0.7), \mathrm{C}_{2 \mathrm{~s}}(0.1) \\
\mathrm{N}_{2 \mathrm{~s}}(0.2)\end{array}$ & $\begin{array}{l}\mathrm{s} \sigma\left(\mathrm{C}_{2 \mathrm{~s}}-\mathrm{O}_{2 \mathrm{~s}}\right)-\mathrm{B} \\
\mathrm{s} \sigma\left(\mathrm{C}_{2 \mathrm{~s}}-\mathrm{N}_{2 \mathrm{~s}}\right)-\mathrm{B}\end{array}$ & $-\mathrm{C}-\mathrm{O},-\mathrm{C}-\mathrm{N}$ \\
\hline $\begin{array}{l}18.0 \\
(16-22)\end{array}$ & $22.71-14.24$ & $\mathrm{C}_{2 \mathrm{~s}}$ & $\mathrm{~s} \sigma\left(\mathrm{C}_{2 \mathrm{~s}}-\mathrm{C}_{2 \mathrm{~s}}\right)-\mathrm{B}$ & $\begin{array}{l}-\mathrm{C}_{6} \mathrm{H}_{4} \\
-\mathrm{C}_{6} \mathrm{H}_{5} \\
\end{array}$ \\
\hline $\begin{array}{l}13.0 \\
(12-16)\end{array}$ & $13.62-10.02$ & $\begin{array}{l}\mathrm{C}_{2 \mathrm{~s}}(0.2), \mathrm{O}_{2 \mathrm{~s}}(0.5) \\
\mathrm{O}_{2 \mathrm{p}}(0.3)\end{array}$ & $\mathrm{p} \sigma\left(\mathrm{C}_{2 \mathrm{~s}}-\mathrm{O}_{2 \mathrm{p}}\right)-\mathrm{B}$ & $-\mathrm{C}-\mathrm{O}$ \\
\hline $\begin{array}{l}9.5 \\
(7-12)\end{array}$ & $9.93-6.37$ & $\begin{array}{l}\mathrm{O}_{2 \mathrm{~s}}(0.1), \mathrm{C}_{2 \mathrm{p}}(0.1) \\
\mathrm{O}_{2 \mathrm{p}}(0.7)\end{array}$ & $\mathrm{p} \pi\left(\mathrm{C}_{2 \mathrm{p}}-\mathrm{O}_{2 \mathrm{p}}\right)-\mathrm{B}$ & $-\mathrm{C}=\mathrm{O}$ \\
\hline $\begin{array}{l}4.5 \\
(4-7)\end{array}$ & $8.02-6.06$ & $\mathrm{C}_{2 \mathrm{p}}(0.4), \mathrm{O}_{2 \mathrm{p}}(0.5)$ & $\begin{array}{l}\mathrm{p} \pi\left(\mathrm{C}_{2 \mathrm{~s}}-\mathrm{C}_{2 \mathrm{~s}}\right)-\mathrm{B} \\
\mathrm{p} \pi \text { (lone-pair)-NB }\end{array}$ & $\begin{array}{l}-\mathrm{C}_{6} \mathrm{H}_{4},-\mathrm{C}_{6} \mathrm{H}_{5} \\
-\mathrm{C}=\mathrm{O},-\mathrm{O}^{-}\end{array}$ \\
\hline
\end{tabular}

WD (difference between observed and calculated peaks) was assumed as $3.0 \mathrm{eV}$.

Table VI. Observed peaks, emission energy, orbital nature, and functional group for X-Ray emission spectra of PMDA-ODA

a) $\mathrm{O} \mathrm{K} \alpha \mathrm{XES}$

\begin{tabular}{|c|c|c|c|}
\hline Observed peak & Emission energy & Orbital nature & Functional oro \\
\hline $\mathrm{eV}$ & {$[(\mathrm{CEBE})-(\mathrm{VIP})] / \mathrm{eV}$} & & \\
\hline \multirow{3}{*}{$\begin{array}{l}527.2 \\
(521-530)\end{array}$} & $527.0-529.7$ & $\mathrm{p} \pi$ (lone-pair)-NB & $=\mathrm{O},-\mathrm{O}^{-}$ \\
\hline & $522.5-525.9$ & $\mathrm{p} \pi$ (lone-pair)-NB & $=\mathrm{O},-\mathrm{O}^{-}$ \\
\hline & $515.2-520.9$ & $\mathrm{p} \pi\left(\mathrm{C}_{2 \mathrm{p}}-\mathrm{O}_{2 \mathrm{p}}\right)-\mathrm{B}$ & $\mathrm{C}^{-} \mathrm{O}^{-}$ \\
\hline
\end{tabular}

b) C K $\alpha$ XES

\begin{tabular}{llll}
\hline \multicolumn{1}{c}{$\frac{\text { Observed peak }}{281}$} & $\frac{\text { Emission energy }}{[(\mathrm{CEBE})-(\mathrm{VIP})] / \mathrm{eV}}$ & & \\
\cline { 1 - 3 }$(280-285)$ & $278.1-282.1$ & $\mathrm{p} \pi\left(\mathrm{C}_{2 \mathrm{p}}-\mathrm{C}_{2 \mathrm{p}}\right)-\mathrm{B}$ & $\mathrm{C}-\mathrm{C}$ \\
\hline & $275.0-277.5$ & $\mathrm{p} \pi\left(\mathrm{C}_{2 \mathrm{p}}-\mathrm{O}_{2 \mathrm{p}}\right)-\mathrm{B}$ & $\mathrm{C}-\mathrm{O}$ \\
277 & $270.2-273.1$ & $\mathrm{p} \pi\left(\mathrm{C}_{2 \mathrm{p}}-\mathrm{C}_{2 \mathrm{p}}\right)-\mathrm{B}$ & $\mathrm{C}-\mathrm{C}$ \\
$(263-280)$ & $264.9-267.7$ & $\mathrm{p} \pi\left(\mathrm{C}_{2 \mathrm{p}}-\mathrm{C}_{2 \mathrm{p}}\right)-\mathrm{B}$ & $\mathrm{C}-\mathrm{C}$ \\
\hline $\begin{array}{l}261.0 \\
(255-262)\end{array}$ & $261.8-263.1$ & $\mathrm{p} \pi\left(\mathrm{N}_{2 \mathrm{p}}-\mathrm{C}_{2 \mathrm{p}}\right)-\mathrm{B}$ & $\mathrm{N}-\mathrm{C}-$ \\
\hline
\end{tabular}

contributions for $\mathrm{p} \sigma-, \mathrm{p} \pi$ - and non-bonding MOs of the polymers. The occupied states of polymers have been investigated with deMon DFT calculations of the model trimer and monomer, and compared with experimental results to identify the origin of spectral features.

\section{REFERENCES}

1. A. St-Amant and D. R. Salahub, Chem. Phys. Lett., 169, 387 (1990); St-Amant A., Ph. D. Thesis, University of Montreal, 1991.

2. J. C. Slater, Adv. Quantum Chem., 6, 1 (1972).

3. P. Duffy and D. P. Chong, Org. Mass. Spectrom., 28, 321 (1993).

4. D. P. Chong, Chem. Phys. Lett., 232, 486 (1995).

5. D. P. Chong, J. Chem. Phys., 103, 1842 (1995).

6. D. P. Chong, C. H. Hu, and P. Duffy, Chem. Phys. Lett., 249, 491 (1996).

7. C. Bureau and D. P. Chong, Chem. Phys. Lett., 264, 186 (1997).

8. K. Endo, Y. Kaneda, M. Aida, and D. P. Chong, J. Phys. Chem. Solids, 56, 1131 (1995).

9. K. Endo, Y. Kaneda, H. Okada, D. P. Chong, and P. Duffy, J. Phys. Chem., 100, 19455 (1996).

10. K. Endo, S. Maeda, and M. Aida, Polym. J., 29, 171 (1997).

11. K. Endo, S. Maeda, and Y. Kaneda, Polym. J., 29, 255 (1997).

12. K. Endo and D. P. Chong, J. Surf. Anal., 3, 618 (1997).

13. S. Kuroki, K. Endo, S. Maeda, D. P. Chong, and P. Duffy, c) $\mathrm{N} \mathrm{K} \alpha \mathrm{XES}$

\begin{tabular}{cll}
\hline $\begin{array}{c}\text { Emission energy } \\
{[(\mathrm{CEBE})-(\mathrm{VIP})] / \mathrm{eV}}\end{array}$ & Orbital nature & Functional group \\
\hline $394.5-397.0$ & $\mathrm{p} \pi$ (lone-pair)-NB & $-\mathrm{N}=$ \\
\hline $392.0-394.4$ & $\mathrm{p} \pi($ lone-pair $)-\mathrm{NB}$ & $-\mathrm{N}=$ \\
$\mathrm{p} \pi\left(\mathrm{N}_{2 \mathrm{p}}-\mathrm{C}_{2 \mathrm{p}}\right)-\mathrm{B}$ & $-\mathrm{N}-\mathrm{C}-$ \\
\hline $387.1-391.4$ & $\mathrm{p} \pi\left(\mathrm{N}_{2 \mathrm{p}}-\mathrm{C}_{2 \mathrm{p}}\right)-\mathrm{B}$ & $-\mathrm{N}-\mathrm{C}-$ \\
\hline $384.7-386.3$ & $\mathrm{p} \pi\left(\mathrm{N}_{2 \mathrm{p}}-\mathrm{C}_{2 \mathrm{p}}\right)-\mathrm{B}$ & $-\mathrm{N}-\mathrm{C}-$ \\
\hline $379.0-383.6$ & $\mathrm{p} \pi\left(\mathrm{N}_{2 \mathrm{p}}-\mathrm{C}_{2 \mathrm{~s}}\right)-\mathrm{B}$ & $-\mathrm{N}-\mathrm{C}$ \\
\hline
\end{tabular}

Polym. J., 30, 142 (1998).

14. K. Endo and D. P. Chong, J. Surf. Anal., 4, 50 (1998).

15. T. Otsuka, K. Endo, M. Suhara, and D. P. Chong, J. Mol. Struct., 522, 47 (2000).

16. U. Gelius and K. Siegbahn, Faraday Discus. Chem. Soc., 54, 257 (1972); U. Gelius, J. Electron Spectrosc. Relat. Phenom., 5, 985 (1974).

17. P. Boulanger, C. Magermans, J. J. Verbist, J. Delhalle, and D. S. Urch, Macromolecules, 24, 2757 (1991).

18. J.-H. Guo, M. Magnuson, C. Săthe, J. Nordgren, L. Yang, Y. Luo, H. Ågren, K. Z. Xing, N. Johansson, W. R. Salaneck, R. Daik, and W. J. Feast, J. Chem. Phys., 108, 5990 (1998).

19. R. P. Winarski, D. L. Ederer, J.-C. Pivin, E. Z. Kurmaev, S. N. Shamin, A. Moewes, G. S. Chang, C. N. Whang, K. Endo, and T. Ida, Nucl. Instrum. Methods phys. Res., Sect B., 145, 401 (1998).

20. R. P. Winarski, D. L. Ederer, E. Z. Kurmaev, S. N. Shamin, K. Endo, T. Ida, A. Moewes, G. S. Chang, S. Y. Kim, and C. N. Whang, Thin Solid Films, 357, 91 (1998).

21. E. Z. Kurmaev, R. P. Winarski, K. Endo, T. Ida, A. Moewes, D. L. Ederer, J.-C. Pivin, S. N. Shamin, V. A. Trofimova, and Yu. M Yarmoshenko, Nucl. Instrum. Methods phys. Res., Sect $B, 155,431$ (1999).

22. E. Z. Kurmaev, A. Moewes, M. Krietemeyer, K. Endo, T. Ida, S. Shimada, R. P. Winarski, M. Neumann, J.-C. Pivin, S. N. Shamin, and D. L. Ederer, Phys. Rev., B 60, 15100 (1999).

23. J. J. Jia, T. A. Callcott, J. Yurkas, A. W. Ellis, F. J. Himpsel, M. G. Samant, J. Stöhr, D. L. Ederer, and R. C. C. Perera, Rev. Sci. Instrum., 66, 1394 (1995).

24. A. R. Williams, R. A. deGroot, and C. B. Sommers, J. Chem. Phys., 63, 628 (1975).

25. J. F. Janak, Phys. Rev., A18, 7165 (1978).

26. L. Asbrink, C. Fridh, and E. Lindholm, Chem. Phys. Lett., 52, 69 (1977).

27. J.-J. Yeh, "Atomic Calculation of Photoionization Cross Section and Asymmetry Parameters" Gordon and Breach Science Publishers, New York, N.Y., 1993.

28. M. J. S. Dewar and E. G. Zoebisch, THEOCHEM 180, 1 
(1988); M. J. S. Dewar, E. G. Zoebisch, E. F. Healy, and J. J. P. Stewart, J. Am. Chem. Soc., 107, 3902 (1985).

29. A. D. Becke, Phys. Rev., A38, 3098 (1988).

30. J. P. Perdew, Phys. Rev., B33, 8822 (1986).

31. G. Beamson and D. Briggs, "High Resolution XPS of Organic Polymers", John Wiley \& Sons, Chichester-New York-Brisbane-Toronto-Singapore, 1992.

32. T. K. Wu and D. W. Ovenell, Macromolecules, 6, 582 (1973).

33. K. Hikichi and M. Yasuda, Polym. J., 9, 1003 (1987).
34. K. Endo, N. Kobayashi, M. Aida, and C. Inoue, J. Phys. Chem. Solids, 54, 887 (1993).

35. P. O. Hahn, G. W. Rubloff, and P. S. Ho, J. Vac. Sci. Technol., A2, 756 (1984).

36. S. P. Kowalczyk, S. Stafström, J. L. Brédas, W. R. Salaneck, and J. L. Jordan-Sweet, Phys. Rev., B: Condens, Matter Mater. Phys, 41, 1645 (1990).

37. H. M. Meyer III, T. J. Wagener, J. H. Weaver, M. W. Feyereisen, and J. Almlöf, Chem Phys. Lett., 164, 5 (1989). 